\title{
A CONCEPÇÃO DE EDUCAÇÃO EMANCIPATÓRIA DE THEODOR W. ADORNO
}

\section{Roselaine Ripa ${ }^{1}$}

\section{Resumo}

A denúncia de Theodor W. Adorno de que a formação cultural se converteu em semiformação socializada, dominando a consciência atual, desencadeia a reflexão sobre como o processo educativo tem se desenvolvido na sociedade administrada. A educação que deveria criticar a sociedade que reproduz a miséria e traz consigo o retorno à barbárie, ao invés disso, visa formar pessoas integradas a ela. À comunidade escolar cabe reconhecer o processo deformativo que a indústria cultural impõe e buscar formas de superá-lo.

Palavras-chave: Educação, Emancipação, Semiformação.

\section{Introdução}

Vivemos em uma sociedade na qual a instrumentalização da razão não permite a verdadeira emancipação do homem em relação à natureza e a si mesmo, mas sim o retrocesso de suas próprias capacidades. Como afirma Adorno, a formação se converteu em semiformação socializada, travando a dimensão emancipatória para fazer imperar a dimensão instrumental da razão. $\mathrm{Na}$ sociedade construída pela indústria cultural, os indivíduos são educados para subordinarem-se ao processo de difusão da semicultura, que prega o conformismo e a satisfação com a fragmentação do todo.

Na sociedade administrada, há um clima que favorece a existência da barbárie, tornando-se necessário questionar esta situação para que formas de intervir possam ser pensadas. A educação poderia ser uma dessas formas, apesar de não ser capaz de fazer muito sozinha. Um processo educativo que rompa com a educação para a disciplina através da dureza, desenvolvendo a auto-reflexão crítica, a autonomia, a reeducação dos sentidos e a relação histórica dos conteúdos culturais poderia contribuir neste processo.

\footnotetext{
${ }^{1}$ Doutoranda do Programa de Pós-graduação em Educação/UFSCar. E-mail: roselaineripa@gmail.com
} Número 10: maio/2008-outubro/2008 
A educação na sociedade administrada

No início do texto Teoria da Semicultura, Adorno (1996) afirma que, para a transformação radical do processo de difusão da semicultura, as reformas pedagógicas isoladas tornam-se insuficientes, sendo necessário modificar as condições objetivas. De fato, há educadores que defendem a urgência de soluções dos problemas educacionais, o que pode contribuir para a subordinação da teoria à prática imediata. Este imediatismo tende a ocultar as verdadeiras exigências sociais e a adiar a possibilidade de auto-reflexão crítica sobre o seu embrutecimento. Com isso, o processo educativo tem contribuído para a subordinação dos indivíduos ao processo de semicultura, desenvolvendo a adaptação, o conformismo e as consciências felizes. Diante desta situação, Adorno ressalta a necessidade de romper com a educação baseada na apropriação de instrumental técnico e receitas de eficiência em detrimento da elaboração do passado e do contato com o não-idêntico.

Adorno afirma que a educação emancipatória poderia auxiliar na realização da autoreflexão crítica da formação que se converteu em semiformação. Porém, é o próprio autor que constata a ausência na literatura pedagógica desta tomada de posição decisiva pela educação para a emancipação e acrescenta que a única possibilidade efetiva da emancipação consiste em que aquelas poucas pessoas interessadas orientem toda a sua energia para que a educação seja uma educação para a contradição e para a resistência.

Por isso, para o pensador frankfurtiano, o objetivo da educação deve ser a emancipação, retomando radicalmente a proposta de Kant (1985, p. 100). “O esclarecimento é a saída do homem de sua menoridade, da qual ele próprio é culpado. A menoridade é a incapacidade de fazer uso de seu próprio entendimento sem a direção de outro indivíduo."

Para Kant, o homem permanece na condição de menor durante toda a vida, aceitando vários tutores, devido à preguiça, à covardia e ao comodismo que possui, designando outras pessoas às tarefas que considera desagradáveis para não precisar esforçar-se e pensar. Os tutores procuram preservar, intimidar e atemorizar o homem, para que este não realize tentativas de esclarecimento e acredite que a sua menoridade é uma natureza.

Porém, o filósofo ressalta que o esclarecimento é possível e com liberdade é inevitável, devendo ocorrer de forma lenta para que o modo de pensar de cada indivíduo seja verdadeiramente reformulado. Os indivíduos que conseguirem pensar por si próprios e 
transformar o estado de menoridade em que se encontram irão promover a avaliação racional do valor e da vocação do homem para pensar por si mesmo.

Segundo Kant, a época em que vivemos precisa ser transformada para que os indivíduos consigam tornarem-se esclarecidos, pois falta muito para que eles façam o uso seguro de sua razão, mas estão livres para "trabalhar e tornarem progressivamente menores os obstáculos ao esclarecimento geral ou à saída deles, homens, de sua menoridade da qual são culpados.” (KANT, 1985, p. 112)

Para Adorno, a educação poderia ser considerada sinônimo de emancipação. Emancipação principalmente da situação em que se encontram os homens, pois cada vez mais se perde o contato com a possibilidade do exercício da autoconsciência crítica. Porém, o capitalismo tardio, através da negação da formação cultural, educa os indivíduos para aceitarem as exigências do processo de difusão da semicultura e as imposições da sociedade administrada.

Diante desta ausência de formação e fundamentado na contribuição filosófica de Kant, Adorno afirma que o esclarecimento ainda é possível, porém quase impossível de se tornar realidade no contexto atual. Adorno considera que o homem esclarecido, emancipado, precisa ter coragem de fazer uso de seu próprio entendimento, pensando por si próprio, questionando os tutores que buscam preservar, intimidar e atemorizar os indivíduos e que impedem que estes realizem as tentativas de esclarecimento.

No ensaio que citei no início (Resposta à pergunta: o que é esclarecimento?), referente à pergunta "vivemos atualmente em uma época esclarecida" Kant respondeu: "Não, mas certamente em uma época de esclarecimento". Nestes termos ele determinou a emancipação de um modo inteiramente conseqüente, não como uma categoria estática, mas como uma categoria dinâmica, como um vir-a-ser e não um ser. (ADORNO, 1995c, p. 181)

Se a emancipação pode ser considerada uma conseqüência, um vir-a-ser, conformar-se com sua ausência de nada contribuiria para sua transformação. O conformismo e a adaptação devem ser substituídos pelo desejo de identificar as dificuldades para atingir a emancipação e, ao mesmo tempo, de opor-se à exigência da sociedade de formar as pessoas de acordo com seus interesses, despertando a consciência dos indivíduos para essa ausência de formação. 
Assim, tenta-se simplesmente começar despertando a consciência quanto a que os homens são enganados de modo permanente, pois hoje em dia o mecanismo da ausência da emancipação é o mundus vult decipi em âmbito planetário, de que o mundo quer ser enganado. A consciência de todos em relação a essas questões poderia resultar dos termos de uma crítica imanente, já que nenhuma democracia normal poderia se dar ao luxo de se opor de maneira explícita a um tal esclarecimento. (ADORNO, 1995c, p. 183)

Com esta análise, Adorno reforça que o processo educativo deve assumir uma posição definitiva em relação à ausência de formação, retomando o conceito de emancipação que se encontra destruído. Porém, a autoridade e a manutenção da ordem são defendidas aleatoriamente no processo educativo, desconsiderando-se a necessidade de desenvolver a autonomia, o questionamento e a emancipação. Muitas vezes, não há espaço para a reflexão, para a autocrítica e para a confrontação de opiniões divergentes.

Segundo Adorno, para que a emancipação possa ser considerada possível, as pessoas devem desenvolver uma firmeza do eu, pois, cotidianamente, muitas delas aceitam o que a existência dominante impõe, representando uma personagem que perpetua a não-identidade delas consigo mesmas.

[...] Gostaria de acrescentar que a emancipação precisa ser acompanhada de uma certa firmeza do eu, da unidade combinada do eu, tal como formada no modelo do indivíduo burguês. A situação atualmente muito requisitada e, reconheço, inevitável, de se adaptar a condições em permanente mudança, em vez de formar um eu firme, relaciona-se, de uma maneira a meu ver muito problemática, com os fenômenos da fraqueza do eu conhecidos pela psicologia. (ADORNO, 1995c, p. 180)

Atualmente tem-se a sensação de que a adaptação a uma nova realidade, a um novo modismo, a uma nova tecnologia é inevitável. O eu parece deixar de existir a cada novo papel que precisa desempenhar. Apesar de cansadas dessa constante troca, as pessoas aceitam uma nova personagem na esperança de se adquirir a tão esperada emancipação. As diferentes personagens que poderiam contribuir para a estruturação da identidade individual, muitas vezes, devido às imposições sociais, contribuem para o enfraquecimento do eu. Segundo Adorno, a tensão entre a autonomia e a adaptação, necessária para que a formação cultural possa acontecer, congela-se no momento adaptativo.

Deste modo, a idéia de emancipação precisa estar presente no pensamento e na prática educacional, considerando-se a influência da ideologia dominante que supera a educação ao 
Revista Sul-americana de Filosofia e Educação - RESAFE

tentar encobrir a consciência do que realmente existe, ultrapassando a adaptação ao existente para fortalecer a resistência.

O resgate da dimensão emancipatória da formação é defendido em uma época na qual a continuidade e a temporalidade estão imobilizadas. A continuidade refere-se à importância dos conteúdos culturais permanecerem presentes no transcorrer do processo ensinoaprendizagem. Porém, o que predomina neste processo é a exigência da memorização de nomes, datas, fatos e fórmulas, que são lembrados apenas para a resolução de uma "prova" e logo são esquecidos mediante a apresentação de um novo conteúdo que precisa ser absorvido imediatamente para a resolução da próxima "prova". Os vínculos temporais entre os diversos objetos de estudo deixam de existir. Evita-se o relacionamento dos conhecimentos atuais com os vistos anteriormente e destes com os interesses e com a história da humanidade. É um processo que reflete a maneira como a semicultura se propaga e, assim, pouco contribui para o resgate da formação cultural. Por isso, tem-se a impressão de que o passado não tem ligação com o presente e nem com o futuro. Isso ocorre porque a indústria cultural propaga que a promessa de felicidade plena está vinculada a um eterno presente, que só consegue prosperar por se calcar na ilusão de que nele consegue-se obter a verdadeira formação cultural.

\section{A concepção de educação emancipatória}

Na sociedade administrada existem aberturas, apesar de estreitas, que possibilitam a crítica da contradição entre as promessas e os seus cumprimentos. Entretanto, como diz Adorno, esta posição crítica torna-se difícil de acontecer, pois toda a continuidade do vínculo entre o pensamento e o questionamento da realidade é interrompida pela indústria cultural. São inevitáveis os prejuízos presentes na dimensão subjetiva do indivíduo, que dão origem à semiformação e à educação danificada. Para o frankfurtiano, a única saída para o resgate da Bildung (formação cultural) é a auto-reflexão crítica sobre a semiformação socializada em que se converteu.

De acordo com Maar (1995), a educação pode ser considerada como um fator de emancipação, mas, para isso, torna-se necessário que haja uma crítica permanente, elaborando-se o passado e criticando-se o presente prejudicado a fim de evitar a repetição da barbárie. Por isso, o autor afirma que a teoria crítica tem a função de analisar a sociedade que 
Revista Sul-americana de Filosofia e Educação-RESAFE

permite a reincidência da barbárie, revelar as suas raízes e descobrir as condições possíveis e necessárias para intervir em relação a sua perpetuação.

O essencial é pensar a sociedade e a educação em seu devir. Só assim seria possível fixar alternativas históricas tendo como base a emancipação de todos no sentido de se tornarem sujeitos refletidos da história, aptos a interromper a barbárie e realizar o conteúdo positivo, emancipatório, do movimento de ilustração da razão. Esta, porém, seria uma tarefa que diz respeito a características do objeto, da formação social em seu movimento, que são travadas pelo seu encantamento, pelo seu feitiço. Por isto a educação, necessária para produzir a situação vigente, parece impotente para transformá-la. (MAAR, 1995, p.12)

Para Adorno, elaborar o passado, como esclarecimento, consiste essencialmente em uma reorientação em direção ao sujeito, ou seja, em um fortalecimento de sua autoconsciência e, portanto, de si mesmo. É neste sentido que o autor afirma ser necessário esclarecer o que se passou, ultrapassando o remorso e a resistência ao horror, para que a elaboração do passado ocorra de forma a eliminar as causas do que aconteceu. "O passado só pode ser elaborado quando as causas que produziram esse passado forem eliminadas. Só porque as causas permanecem é que até hoje sua maldição não pôde ser exorcismada.” (ADORNO, 1992, p.30)

Segundo Adorno, na Alemanha, predomina a falta do domínio do passado, que é justificada através do complexo de culpa coletivo. Muitas pessoas alegam que nada sabiam ou demonstram indiferença à deportação e ao genocídio. Outras recorrem a contra-argumentos contabilizando as mortes ou afirmando que as vítimas deram motivos quaisquer. Esta tendência histórica leva à destruição da memória e, com ela, da lembrança, sendo considerado até mesmo doentio ocupar-se do passado. Para continuar se identificando e se adaptando a esta realidade que traz consigo a reincidência da barbárie, as pessoas abdicam do próprio eu, da história da humanidade e da condição de não-emancipadas. Porém, quando as pessoas percebem que o eu encontra-se enfraquecido, que a história da humanidade é desconsiderada e assumem a condição de seres não-emancipados optando por superá-la, poderiam estar criando caminhos para a formação cultural ocorrer.

Porém, destruir a memória, a lembrança e o tempo tornam-se os princípios da sociedade da indústria cultural, que se propõe a adaptar o indivíduo ao existente e não a criar condições para que ele possa transformá-lo. "Quando a humanidade abre mão de suas 
Revista Sul-americana de Filosofia e Educação - RESAFE

lembranças e se rebaixa acomodando-se às conjunturas atuais, estamos na presença de uma lei de desenvolvimento objetivo." (ADORNO, 1992, p.19)

Portanto, para a elaboração do passado torna-se necessário realmente esclarecer o que passou, fazendo com que os sujeitos reflitam sobre os mecanismos que provocam a reincidência da barbárie, reforçando a sua auto-consciência e o seu eu. Adorno denuncia que, na sociedade construída pela indústria cultural, o perigo permanece e que o conhecimento que poderia proporcionar a emancipação dos indivíduos encontra-se travado.

Uma indústria cultural exacerbada acaba por lhes vedar a visão num contexto ofuscante; trava o doloroso esforço em busca de um conhecimento que poderia enriquecer suas vidas. A necessidade dessa adaptação, dessa identificação com o existente, com o dado, com o poder como poder, cria o potencial do totalitarismo. (ADORNO, 1992, p. 25-26)

A pouca atenção dada à monstruosidade que aconteceu em Auschwitz, por exemplo, demonstra a possibilidade de tal fato voltar a ocorrer, pois a barbárie encontra-se atrelada à própria civilização, tal como destacou Adorno (1994a, p. 33) ao reafirmar a frase de Freud de que "a civilização produz a anticivilização e a reforça progressivamente."

Por isso, a educação só poderá contribuir para a emancipação dos indivíduos se assumir como princípio a oposição à barbárie e reconhecer que as condições que a possibilitaram ainda encontram-se presentes. Segundo Adorno, a educação, desde a primeira infância, deveria criar um clima espiritual, cultural e social que não possibilitasse uma repetição de Auschwitz, tornando consciente, na medida do possível, os motivos que levaram ao horror.

Deste modo, Adorno justifica a necessidade dos indivíduos serem confrontados com os fatos e envolvidos em um processo formativo baseado na autonomia, na capacidade de reflexão e na auto-determinação. Para o pensador frankfurtiano, a educação só terá sentido se for uma educação para a auto-reflexão crítica. "A única verdadeira força contra o princípio de Auschwitz seria a autonomia, se é que posso utilizar a expressão de Kant; a força para a reflexão, para a autodeterminação, para a não-participação.” (ADORNO, 1994a, p. 37)

Porém, Adorno denuncia que na sociedade administrada a predominância ainda é a da educação para a disciplina através da dureza, que tem o objetivo de formar indivíduos integrados a ela. $\mathrm{O}$ autor explica que este processo educativo utiliza uma prática 
sadomasoquista, que faz com que os indivíduos suportem a dor e reprimam o medo. A pessoa torna-se dura consigo mesma e acredita ter o direito de ser assim com as demais.

Aquele que é duro contra si mesmo adquire o direito de sê-lo contra os demais e se vinga da dor que não teve a liberdade de demonstrar, que precisou reprimir. Esse mecanismo deve ser conscientizado, da mesma forma como deve ser fomentada uma educação que não mais premie a dor e a capacidade de suportá-la. (ADORNO, 1994a, p. 40)

Para Adorno, a imagem da educação pela dureza, na qual muitos acreditam de forma irrefletida, é equivocada. A crença de que a virilidade é medida pela capacidade para suportar a dor se transformou em símbolo de um masoquismo que, como reforça a Psicologia, encontra-se com muita facilidade aliado ao sadismo. O aluno é elogiado quando consegue mostrar-se indiferente à dor, acreditando adquirir o direito de também ser duro com os demais. Por isso, Adorno acredita que este processo precisa ser evitado através da eliminação de uma concepção de educação que premie a dor e a capacidade de suportá-la.

A educação para a dureza como majoritária no contexto social vigente contribui para o surgimento de tendências regressivas e para a formação de pessoas com traços sádicos reprimidos. "Sempre que o consciente estiver mutilado, isso reverte para o corpo e para a esfera somática, numa forma sem liberdade, tendente à violência.” (ADORNO, 1994a, p. 38)

Neste contexto, Adorno apresenta a ambigüidade presente na prática esportiva, pois há a possibilidade de se desenvolver o companheirismo e a consideração para com o mais fraco, mas também a agressão, a crueldade e o sadismo. Não apenas entre os jogadores, que usam palavras de baixo calão ou anedotas preconceituosas contra o adversário, mas também entre os torcedores.

Porém, não é só no esporte que observamos estas manifestações. A perpetuação de atitudes sadomasoquistas pode ser vistas cotidianamente na sociedade construída pela indústria cultural. Algumas são percebidas porque são divulgadas com fervor pela mídia, com o objetivo de gerar audiência e não o de contribuir para a reflexão sobre estas práticas. Outras são ignoradas por serem consideradas banais. Os grupos que buscam eliminar as minorias excluídas, como os skinheads, mutilam e matam como se estas atitudes fizessem parte de sua natureza. Parecem acreditar mesmo que possuem este direito e o praticam como se fosse um favor para a sociedade. As agressões físicas e psicológicas realizadas durante os trotes universitários só despertaram a necessidade de rever estas práticas quando um deles causou a 

morte de um dos chamados "bixos" e tal fato teve repercussão nacional. Mas, mesmo assim, continuam sendo praticados e perpetuando atitudes sadomasoquistas. No dia-a-dia escolar, há o estímulo à competição, que, nas palavras de Adorno, é uma atitude contrária à educação emancipatória. O professor elogia os alunos que se adaptam, aqueles que não questionam, aqueles que aceitam incondicionalmente o que está sendo proposto, enfim, aqueles que não fazem barulho. Ao mesmo tempo, exclui os que não se enquadram no que está planejado, e a estes restam as expulsões, as suspensões ou os gritos.

Como consequiência deste processo sadomasoquista, muitas pessoas se omitem como seres autodeterminantes e passam a possuir o que Adorno denominou de "consciente coisificado". Elas tornam-se incapazes de vivenciarem experiências humanas, de serem emotivas e de pensarem sobre as conseqüências de seus atos. Também são pessoas que tendem a se equiparar às coisas e a considerar os outros também como coisas.

A consciência coisificada, que se entende mal a si mesma como se fosse natureza, é ingênua: toma a si mesma - algo que veio a ser e que é completamente mediado em si - como se fosse, conforme expressão de Husserl, a esfera do ser das origens absolutas, e àquilo que ela arma diante dela como sendo a coisa tão ansiada. (ADORNO, 1995e, p. 192)

Adorno ressalta que a utilização da tecnologia como um fim em si mesma, cujas finalidades são encobertas, fez com que as pessoas desenvolvessem um sistema mais eficiente para transportar outras pessoas de forma mais rápida à Auschwitz, sem considerar o que poderia acontecer com elas. Para o autor, as pessoas que tendem para a fetichização da tecnologia são pessoas frias e incapazes de amar, pois seu amor foi absorvido pelas máquinas.

A educação após Auschwitz deve se opor a estes aspectos presentes na sociedade administrada, desenvolvendo o calor humano, conscientizando as pessoas da frieza e dos mecanismos subjetivos que geram a barbárie, preparando um clima desfavorável para que o horror não se repita.

Para isso, Adorno enfatizou a necessidade de se educar os educadores, levando-os a refletir sobre a sua atuação profissional e a sua relação com o todo social. Segundo o autor, os educadores devem ter uma formação cultural como experiência própria, superando o pensamento conformista e adaptado ao existente. Além disso, o interesse, o esforço espontâneo e o entusiasmo seriam fundamentais para que os professores pudessem se abrir a elementos do espírito e desenvolver a capacidade de amar. 
Porém, a formação de pessoas cujo espírito associe-se a um comportamento livre e autônomo, que Adorno considera fundamental aos educadores, não foi percebida por ele na prova geral de Filosofia dos concursos para a docência em ciências nas escolas superiores do estado de Hessen, na Alemanha.

A colcha de retalhos formada de declamação ideológica e de fatos que foram apropriados, isto é, na maior parte das vezes decorados, revela que foi rompido o nexo entre objeto e reflexão. A constatação disso nos exames é decorrente, levando imediatamente a concluir pela ausência da formação cultural (Bildung) necessária a quem pretende ser um formador. (ADORNO, 1995b, p. 63)

Esta é uma constatação que muitos professores não aceitam. Eles acreditam que possuem o saber, por isso, tornam-se diante dos alunos os detentores do conhecimento e os ditadores de comportamentos, ignorando a ausência de formação a que eles próprios são submetidos pelo processo de difusão da semicultura. Por isso, muitas vezes, o professor é visto pelos alunos como aquele que distribui conhecimentos, ou como herdeiro do carrasco, aquele que castiga. Ambas as situações trazem consigo uma aversão à sua imagem.

Segundo Adorno, o professor é envolvido pela sociedade e pela profissão em um jogo desonesto, pois como docente acredita ter o dever de castigar e de utilizar seus conhecimentos como vantagem perante o saber dos alunos. Com isso, o processo formativo em que os alunos estão envolvidos encontra-se baseado na autoridade do professor. Em muitas situações, ele assume o papel de influenciar, convencer ou iludir, o que perpetua a ausência da possibilidade de se desenvolver a emancipação dos que estão sob a sua tutela.

Para reverter esta situação, Adorno afirma a necessidade do professor modificar seu comportamento. E, com esta mudança, ser capaz de contribuir, como educador, para o desenvolvimento de uma consciência verdadeira dos indivíduos. É esta a concepção de educação política que Adorno propõe durante o processo formativo.

Evidentemente não a assim chamada modelagem de pessoas, porque não temos o direito de modelar pessoas a partir do seu exterior; mas também não a mera transmissão de conhecimentos, cuja característica de coisa morta já foi mais do que destacada, mas a produção de uma consciência verdadeira. Isto seria inclusive da maior exigência política; sua idéia, se é permitido dizer assim, é uma exigência política. (ADORNO, 1995d, p. 141) 
Neste sentido, a idéia de emancipação deve estar presente no pensamento e na prática educacional como uma exigência política. A influência da ideologia dominante precisa ser percebida, pois trava o processo educativo ao tentar encobrir a consciência do que realmente existe. O esforço para tentar moldar os indivíduos necessita ser destinado para a possibilidade de se desenvolver a reflexão crítica, a criatividade, a ousadia e a resistência. Apesar de se orgulhar pelos números de matrículas conseguidas, pela inclusão de todos os alunos e pela tecnologia aplicada à educação, o fracasso de todos os processos formativos desenvolvidos na escola pode ser percebido através da perpetuação da barbárie na sociedade em que vivemos. Segundo Adorno, a barbárie seria o contrário da formação e a desbarbarização torna-se o pressuposto para a sobrevivência da humanidade.

\section{Considerações Finais}

Segundo Adorno, a práxis pedagógica deve realizar uma autocrítica sobre seu desenvolvimento, revelando as diferenças que existem entre o que se pretende e o que se faz, entre a teoria e a prática. Também deve possibilitar a efetivação de um clima cultural que favoreça a construção de uma identidade autocrítica, combatendo os elementos subjetivos e objetivos que, através do processo formativo atual, debilitam o ego. Portanto, deve se opor à educação pela dureza que reprime o medo, deforma os indivíduos e reforça a prática sadomasoquista.

Como afirma Adorno, para que a dimensão da emancipação da cultura possa ser resgatada, torna-se necessária a retomada coletiva do exercício da auto-reflexão crítica, capaz de resgatar a autonomia, a reflexão, a suspeita, a criatividade, a capacidade de percepção e intelectualidade.

Adorno afirma que ainda é possível trabalharmos para a identificação da barbárie atual, com o propósito de efetivar a sua transformação. Como afirma o autor no texto Sobre música popular: "Para ser transformado em um inseto, o homem precisa daquela energia que eventualmente poderia efetuar sua transformação em homem”. (ADORNO, 1994b, p. 146) 


\section{Referências}

ADORNO, T. W. O que significa elaborar o passado? Tradução de Newton Ramos-deOliveira. In: RAMOS-DE-OLIVEIRA, N. (org.). Quatro Textos Clássicos. São Carlos-SP: UFSCar, 1992. Publicação interna.

ADORNO, T. W. Educação após Auschwitz. In: COHN, G. (Org.). Theodor W. Adorno. São Paulo: Ática, 1994a.

ADORnO, T. W. Sobre Música Popular. In: COHN, G. Theodor W. Adorno. São Paulo: Ática, 1994b.

ADORNO,T.W. A Educação Contra a Barbárie. In Educação e Emancipação. Tradução Wolfgang Leo Maar. Rio de Janeiro: Paz e Terra, 1995a.

ADORNO, T.W. A Filosofia e os Professores. In: Educação e Emancipação. Tradução Wolfgang Leo Maar. Rio de Janeiro: Paz e Terra, 1995b.

ADORNO, T.W. Educação e Emancipação. In: Educação e Emancipação. Tradução de Wolfgang Leo Maar. Rio de Janeiro: Paz e Terra, 1995c.

ADORNO, T.W. Educação - Para quê? In: Educação e Emancipação. Tradução Wolfgang Leo Maar. Rio de Janeiro: Paz e Terra, 1995d.

ADORNO, T.W. Palavras e sinais: modelos críticos 2. Tradução Maria Helena Ruschel/ Supervisão de Álvaro Valls. Petrópolis, Rio de Janeiro: Vozes, 1995e.

ADORNO, Theodor. W. Teoria da Semicultura. Tradução Newton Ramos-de-Oliveira com col. de Bruno Pucci e Cláudia de Moura Abreu. In: Educação e Sociedade. Campinas: Papirus. Ano XVII, no.56, dez.1996, pp. 388-412.

KANT, I. Resposta à Pergunta: que é Esclarecimento? In: KANT, I. Textos Seletos. Tradução de Raimundo Vier e Floriano de Sousa Fernandes. Petrópolis: Vozes, 1985.

MAAR, W. L. À Guisa de Introdução: Adorno e a Experiência Formativa. In: ADORNO, T.W. Educação e Emancipação. Tradução de Wolfgang Leo Maar. Rio de Janeiro: Paz e Terra, 1995. 